\title{
Earthquake source mechanisms in onshore and offshore Nordland, northern Norway
}

\author{
Ilma Janutyte' \& Conrad Lindholm
}

\author{
${ }^{1}$ NORSAR, 2027 Kjeller, Norway. \\ E-mail corresponding author (Ilma Janutyte): ilma@inbox.lt
}

\begin{abstract}
In this paper we present a comprehensive database of 152 earthquake focal mechanism solutions for the Nordland area, northern Norway, and the adjacent offshore regions. 123 focal mechanisms are published for the first time. We developed an equation to objectively determine the quality of the focal mechanisms, while the equation was explicitly adjusted to the used dataset (not globally accepted). We used the equation to assign quality factors to the new focal mechanisms, while the quality of the earlier published focal mechanisms was kept as originally provided. About $20 \%$ of all focal mechanisms were set to the higher quality A and B, which was assigned to the onshore earthquakes only, whereas for offshore earthquakes the highest assigned quality was quality $\mathrm{C}$, mostly due to larger azimuthal gaps. The results showed that seismicity onshore and offshore Nordland is different in type: with dominant shallow, normal-faulting earthquakes onshore and mostly deeper, mixed type faulting earthquakes offshore, while along the coast the faulting regime was mostly normal to strike-slip. The results indicated that maximum horizontal compressional stress, $\sigma_{\mathrm{H}}$, directions in the offshore areas on a large scale originate from the plate-tectonic ridge push with NW-SE compression, whereas in the onshore regions $\sigma_{H}$ directions are better explained through local stress-generating sources, such as topography. In our results we also recognised a possible relation between the Svartisen glacier massif and the enhanced seismicity in the surroundings, including an earthquake swarm activity to the west of the glacier. Moreover, in many onshore and offshore regions the nodal plane azimuths, obtained from the focal mechanisms, correlate well with the trends of geologically mapped onshore and offshore structures.
\end{abstract}

Keywords: focal mechanisms; Nordland; quality ranking system; stress axis; earthquake swarm

Electronic Supplement 1: Focal mechanisms

Received 9. April 2017 / Accepted 15. September 2017 / Published online 24. October 2017

\section{Introduction}

While the nature of earthquakes is not well understood in territories with complex geological and tectonic conditions, it is known that they generally occur along pre-existing zones of weakness and result from a buildup of stress and reduced effective shear strength along favourably oriented faults (e.g., Sibson, 1985). We also use these perspectives in our current attempt to interpret new focal mechanism results for the Nordland region of northern Norway.

The Nordland region, both onshore and offshore, exhibits one of the highest seismic activity rates in northern
Norway. Although the earthquakes are mostly weak to moderate, the area has hosted the largest known historical earthquake of northern Europe in the last two centuries - the magnitude M 5.8 earthquake near Lurøy, at the mouth of Ranafjord in 1819 (Muir-Wood, 1989; Bungum \& Olesen, 2005). In addition, several shallow earthquake swarms have previously been reported around Meløy and Steigen (e.g., Atakan et al., 1994; Hicks et al., 2000a; Bungum et al., 2010).

The NEONOR2 project (Neotectonics in Nordland - Implications for petroleum exploration; https://www.ngu.no/en/neonor2) aimed to improve our 
understanding of neotectonic crustal deformations, stress regime and the overall seismicity pattern in Nordland and the adjacent offshore areas. In the frame of the project, from August 2013 to May 2016, along the coast of Nordland - from Ranafjord in the south to Vesterålen in the north and also in the Lofoten archipelago - a temporary network of 27 seismic stations was deployed alongside the permanent Norwegian National Seismic Network (NNSN; Fig. 1). Using data from both the temporary and the permanent deployments 1242 earthquakes were located in the study area, including an earthquake swarm. In an earlier study (Janutyte et al., 2017) we used the seismological monitoring results to obtain the seismicity distribution and identify the relation between the observed earthquakes and the major tectonic structures in the area, while our current study is focused on the focal mechanisms of the earthquakes, and aims to reveal the underlying stress-generating mechanisms.

\section{Tectonic settings: stress sources and earthquake depths}

The studies of Osmundsen et al. (2009) and Redfield \& Osmundsen (2013) concluded that the uplift and landscape-forming tectonic activity in Norway are recent and even ongoing. The NEONOR1 project (Dehls \& Olesen, 2000) conducted in Nordland in 1997-2000 could not convincingly verify that the observed surface features were truly of neotectonic origin. Consequently, the possibility could not be excluded, and it became the background for a second-phase investigation that was carried out in the framework of the NEONOR2 project during the years 2013-2017.

The geological conditions in the study area are very complex. Mainland Nordland is dominated by the Upper

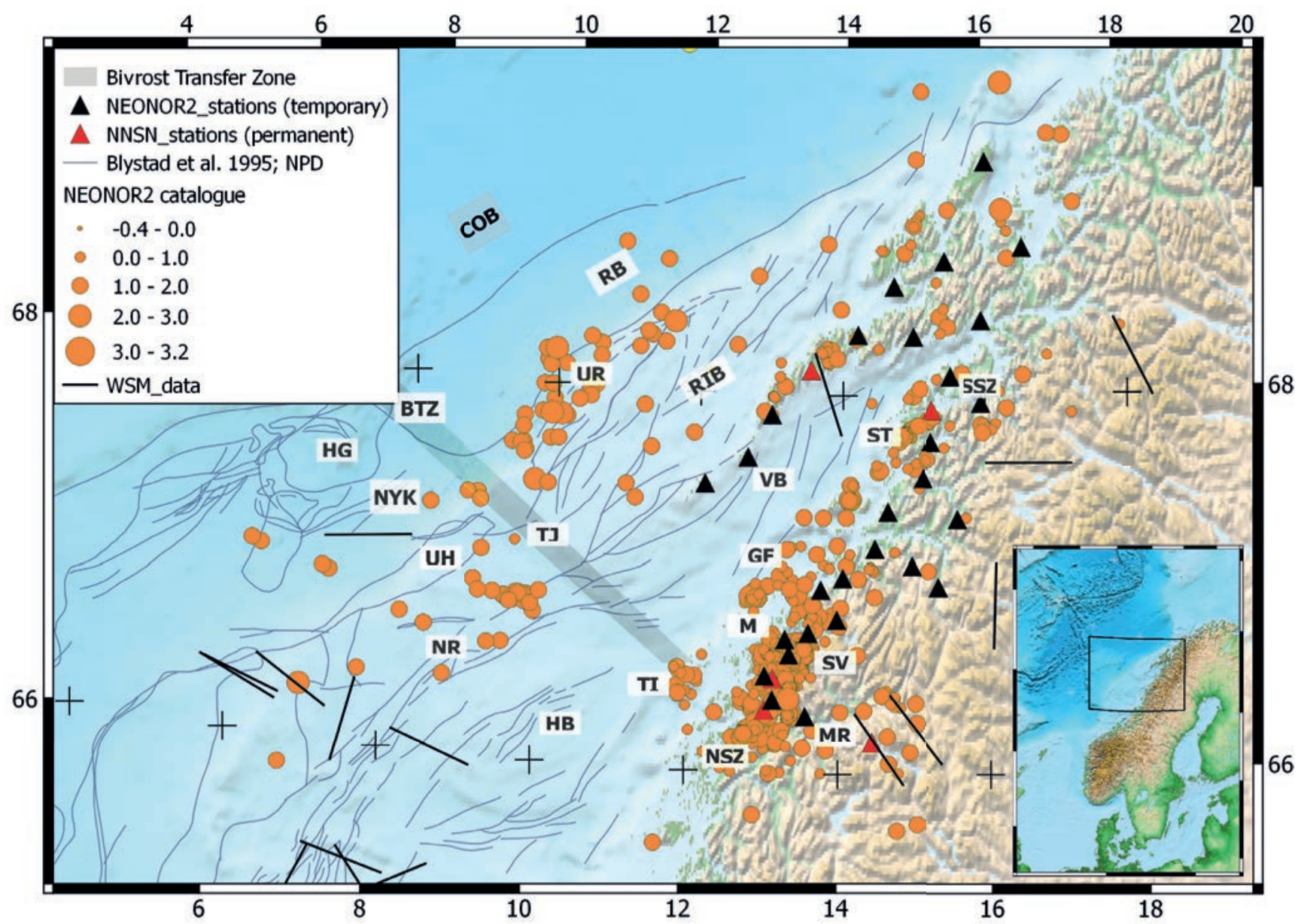

Figure 1. Map of the study area of Nordland, northern Norway (see Inset), showing the seismic network together with the newly obtained earthquake distribution, and the main geological features. Black triangles - the temporary NEONOR2 seismic stations, red triangles - permanent seismic stations of the Norwegian National Seismic Network, orange disks - 1242 earthquakes recorded during the NEONOR2 project from August 2013 to May 2016, black rods - compressional stress directions from the World Stress Map project. Tectonic structures and sites: BTZ Bivrost transfer zone, COB - Continent-Ocean Boundary, GF - Grønna fault, HB - Helgeland Basin, HG - Hel Graben, M-Meløy, MR - Mo i Rana, NR - Nordland Ridge, NSZ - Nesna Shear Zone, NYK - Nyk High, RB - Røst Basin, RIB - Ribban Basin, SSZ - Sagfjord Shear Zone, ST - Steigen, SV - Svartisen, TI - Treena Island, TJ - Trøenadjupet, UH - Utrøst High, UR - Utrøst Ridge, VB - Vestfjorden Basin (Blystad et al., 1995; Olesen et al., 2002). 
and Uppermost Allochthons that were thrust onto the lower nappes and Precambrian basement during the Scandian continent-continent collision in Silurian and Devonian times (Roberts \& Gee, 1985). In the Devonian period, the nappes were dismembered by a late gravitational collapse of the Caledonian orogen (Rykkelid \& Andresen, 1994; Braathen et al., 2002; Eide et al., 2002). This complex and deformed upper crust hides faults and structures of which only a few have been mapped in detail, and the offshore-onshore connections of these structures have been only partly mapped. For the onshore areas, the seminal work of Gabrielsen et al. (2002) is the best existing database, while for the offshore areas the main structures are reasonably well mapped and described by Blystad et al. (1995) and later refined by others (e.g., Osmundsen et al., 2002).

In Fennoscandia, the stress indicators (i.e., earthquake focal mechanisms and shallow borehole measurements) at a regional scale consistently indicate a maximum horizontal principal stress, $\sigma_{\mathrm{H}}$, of NW-SE trend that is perpendicular to the Mid-Atlantic Ridge, which indicates an influence of plate-tectonic motions and ridge push (Richardson et al., 1979; Pascal et al., 2005; Heidbach et al., 2008; Gregersen \& Voss, 2009). The far-field stress modelling by Pascal \& Gabrielsen (2001) around the northern North Sea and the mid-Norwegian margin showed that the relatively strong oceanic crust allows conservation of the applied boundary strain throughout the oceanic domain, and the boundary strain is almost totally transferred to the margin. This explains the NW-SE to WNW-ESE stress direction. Pascal et al. (2010) concluded that the present-day stress pattern in Fennoscandia is mostly governed by the ridge push and not by residual glacial loading stresses. However, many studies (e.g., Stroeven et al., 2016) have concluded that the influence of the regional Fennoscandian uplift is significant along Norwegian coastal areas, and there has also been reported an influence from a possible 'coastal bending' (e.g., Gudmundsson, 1999; Hicks et al., 2000a) due to a combination of onshore postglacial uplift, offshore sediment loading and a steep topographic relief (Olesen et al., 2013). Byrkjeland et al. (2000) and Fejerskov \& Lindholm (2000) have suggested that regional and local stress factors, such as flexural stresses from sedimentary loading together with favourably oriented and sufficiently weak faults, are also required to explain the occurrence and distribution of earthquakes in the Nordland region. This was also supported by conclusions of Redfield \& Osmundsen (2013) that the seismicity in northern Norway could be controlled more by the local vertical loads from the local topography than by the horizontal far-field forces. Thus, stress-generating forces of global, regional and local origin are all possible sources for the observed seismicity. However, it is far from well understood how each of the different components interact and contribute to the overall stress field and local deformations.
Offshore Nordland, the passive continental margin shows clear seismic activity along certain segments (Fig. 1), a feature that was also found by Hicks et al. (2000a). According to Jaeger et al. (2007), earthquakes along the continental shelf can also be caused by stress concentration related to density-contrasting materials, i.e., along the contact between the oceanic crust and the continental crust, as was also suggested by Fejerskov \& Lindholm (2000). Moreover, it was earlier shown that offshore earthquakes are generally deeper (at least 15 $\mathrm{km}$ deep) and generally of reverse-fault character, which may be explained by large lateral structural variations (Bungum et al., 1991; Hicks et al., 2000b; Bungum et al., 2010).

Hicks et al. (2000a) and Byrkjeland et al. (2000) concluded that the maximum post-glacial uplift gradients around the Mo i Rana area follow the coast quite closely, which might be a main reason for the enhanced seismic activity in the region. They also found that the earthquakes were predominantly of normal to strike-slip faulting type, reflecting largely on a coast-perpendicular extensional regime (i.e., extensional stresses trending NW-SE). Olesen et al. (2013) concluded that some strike-slip earthquakes with coast-parallel compression could be associated with the locally enhanced uplift pattern and the related flexuring mechanism. Ttherefore, a coast-perpendicular extension could also be expected, as the crust may still be strongly flexed due to the recent erosion.

Two earlier reported earthquake swarms in the Nordland region around Meløy in 1978-1979 (Bungum et al., 1979) and Steigen in 1992 (Atakan et al., 1994) revealed mostly shallow earthquake hypocentres of 2 to $8 \mathrm{~km}$ depth. The Steigen swarm events were mostly of an oblique-normal faulting nature (Atakan et al., 1994), whereas the Meløy events resulted in mostly normal (Bungum et al., 1979; Bungum et al., 1982) and strike-slip (Vaage, 1980) faulting. From the NEONOR1 data collected in the Mo i Rana area during the 18 months of the monitoring, Hicks et al. (2000a) reported on several small swarm-like earthquake groups to the north of Ranafjord. These swarm-like events occurred mostly along NNW-SSE-trending lineaments, while some of the groups were seismically active only for a couple of months. The registered earthquakes were mostly along normal to strike-slip faults and their hypocentres in different groups varied from 4 to $12 \mathrm{~km}$ depth.

The most recent earthquake swarm activity was observed during the NEONOR2 project from April 2015 to about March 2016 to the west of Svartisen. During the swarm activity there were recorded several hundreds of small earthquakes and most of them were shallow, 3 to $8 \mathrm{~km}$ deep (Janutyte et al., 2017), similar to the earlier reported earthquake swarms. 


\section{Dataset of focal mechanisms}

From August 2013 to May 2016 the temporary NEONOR2 seismic network in the Nordland area recorded 1242 local earthquakes with magnitudes ranging from M -0.4 to 3.2 (Fig. 1). Due to the seismic network deployed on the mainland, the onshore earthquakes were recorded with a lower detection threshold and smaller azimuthal gaps compared to the earthquakes offshore. Also, usage of a robust 1-D velocity model in the region with such significant geological and tectonic variations (e.g., Maystrenko et al., 2017) led to an inherent uncertainty in the earthquake locations, and subsequently to the final focal mechanism results - a location precision that cannot be easily improved.

From all the located earthquakes we obtained 123 focal mechanisms (Fig. 2). In our analysis we also included focal mechanism solutions from earlier studies, such that our final dataset consists of 152 focal mechanisms (Electronic Supplement 1). To derive the new focal mechanisms we used three well-known algorithms: FOCMEC (Snoke et al., 1984), HASH (Hardebek \& Shearer, 2002) and FPFIT (Reasenberg \& Oppenheimer, 1985), which are all integrated into the SEISAN program package (Ottemoller et al., 2016). The data used for calculating the earthquake focal mechanisms were firstmotions of P-phases with distinguishable polarities, and $\mathrm{P} / \mathrm{S}$ amplitude ratios observed at the stations where the first arrivals were the direct phases (i.e., omitting reflected and refracted phases). The amplitude estimations for Pand $\mathrm{S}$-waves were conducted on vertical and rotated, transverse, horizontal components (SH), respectively. We analysed the results obtained with the three methods and stability of the solutions across different algorithms in order to ensure maximum reliability of the results. In this paper, we present the focal mechanism solutions (Electronic Supplement 1) obtained with the FOCMEC program, which was found to be superior in terms of stability and robustness compared to the FPFIT and HASH programs, as in FPFIT the $\mathrm{P} / \mathrm{S}$ amplitude ratios are not used, while FOCMEC also provides better control on managing errors in the final solution compared with the HASH program.

\section{Quality assessment of the focal mechanisms}

Quality characterisation of earthquake focal mechanisms is generally conducted through a four-level alphabetical system where A stands for best quality and D for lowest quality (i.e., less trustworthy) results. The World Stress Map project (WSM, http://www.world-stress-map. org/) introduced a quality ranking based on Zoback \& Zoback (1989), and the ranking has been improved over the years and most recently by Heidbach et al.
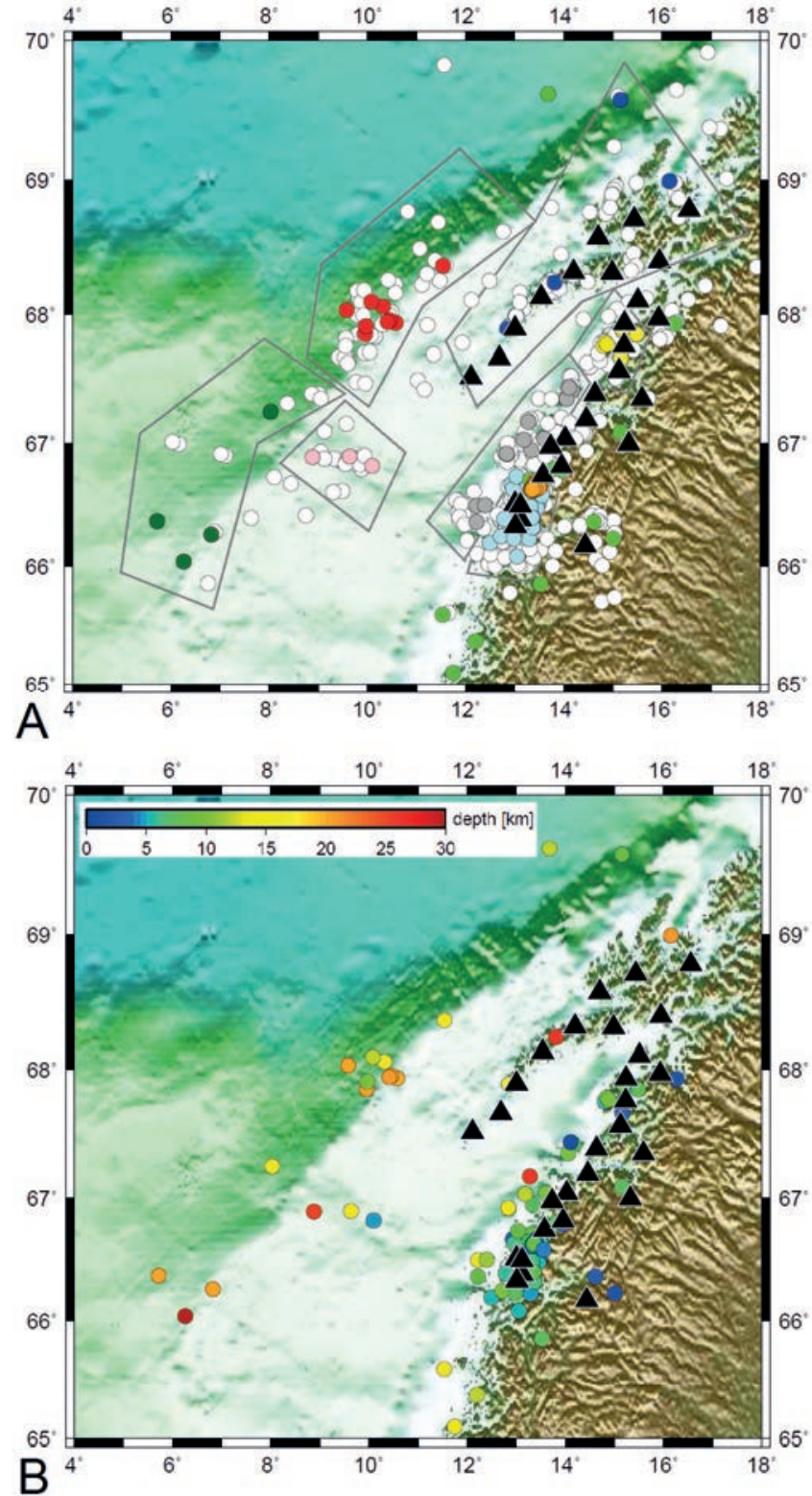

Figure 2. (A) Distribution of seismicity obtained during the NEONOR2 project (white discs) and distinct groups of earthquakes with defined focal mechanisms (coloured discs): dark green - southern part of the shelf edge, red - northern part of the shelf edge, pinkTrenadjupet, grey - coastline, orange - west of Svartisen, light blue - SW of Svartisen, yellow - Steigen area, dark blue - Lofoten area, light green - not grouped single earthquakes. (B) Hypocentre depths of 152 earthquakes with defined focal mechanisms. The distribution of hypocentre depths shows a general tendency for shallower earthquakes onshore and somewhat deeper offshore and in the Lofotens. Black triangles show the seismic stations of the temporary NEONOR2 project and the permanent Norwegian National Seismological Network.

(2010). While generally appreciating the seminal work that was conducted in developing the ranking system, we recognised that the WSM recommendations would prevent an effective quality determination (and comparison) when dealing with a dataset like ours. If we had followed the WSM recommendations, the majority of the obtained focal mechanisms, especially in the offshore 
areas, would have been assigned to only the lowest quality $\mathrm{D}$ due to large azimuthal gaps. Therefore, we designed a quality scale that was adapted to the data on hand, and it turned out to be applicable and useful for a relative characterisation of the new 123 focal mechanisms.

Our developed equation for quality determination takes into account the uncertainties of event location (i.e., time residual and azimuthal gaps), number of observations (both first-motion polarity picks and $\mathrm{P} / \mathrm{S}$ amplitude ratios) and consistency across the independently obtained focal mechanism solutions using three different algorithms (i.e., FOCMEC, FPFIT and HASH). Again, we want to emphasise that the developed quality scale is not globally applicable, but specifically adjusted for the NEONOR2 dataset analysed herein.

In our developed scale the quality factor, $q f$, is defined as follows:

$q f=o b s * 0.1-c o m p * 0.4-r e s * 0.2-g a p * 0.9+1.5$

where obs is the observation factor that includes both the amount of polarity readings, $p o l$, and $\mathrm{P} / \mathrm{S}$ amplitude ratios, amp, and the amount of errors of the polarities, pol_err, and the amplitude ratio errors, amp_err, in the best fitting solution obtained with the FOCMEC program:

$o b s=p o l-p o l_{-} e r r+0.5^{\star}\left(a m p-a m p \_e r r\right) ;$

comp is the compatibility factor among the focal mechanism solutions obtained using the three calculation methods; res is the factor of travel time residual (RMS) in the final event location; and gap is the factor defining the azimuthal gap in the final event location. The value of comp ranges from 0 (perfect fit) through 1 (good fit) to 2 (reasonable fit); value is set to 0 for RMS $<0.6 \mathrm{sec}$, to 1 for $0.6 \leq \mathrm{RMS} \leq 0.9 \mathrm{sec}$, and to 2 for RMS $\geq 1.0 \mathrm{sec}$; and the gap value is set to 0 for gap $<90^{\circ}$, to 1 for $90^{\circ} \leq$ gap $<160^{\circ}$, and to 2 for gap $\geq 160^{\circ}$.

We designed Eq. 1 in such a way that most of the results are kept within approximate boundaries from 0 to 3 , and the digital of value is then transformed into a quality factor using the general mathematical rounding concept: $q f \geq 2.5$ for quality A, $1.5 \leq q f<2.5$ for quality B, $0.5 \leq q f$ $<1.5$ for quality $\mathrm{C}$, and $q f<0.5$ (also negative) for quality D (Fig. 3).

While analysing our dataset we concluded that 10 observations per event is a reasonable number to obtain good-quality results, therefore, we set the multiplication factor of 0.1 (Eq. 1) for weighting the number of observations. The multiplication factor for the azimuthal gap was set to 0.9 indicating its major significance, since better azimuthal coverage generally yields more reliable focal mechanism solutions. Moreover, as comp and res generally have less influence on the focal mechanism precision compared to the azimuthal gap, we assigned
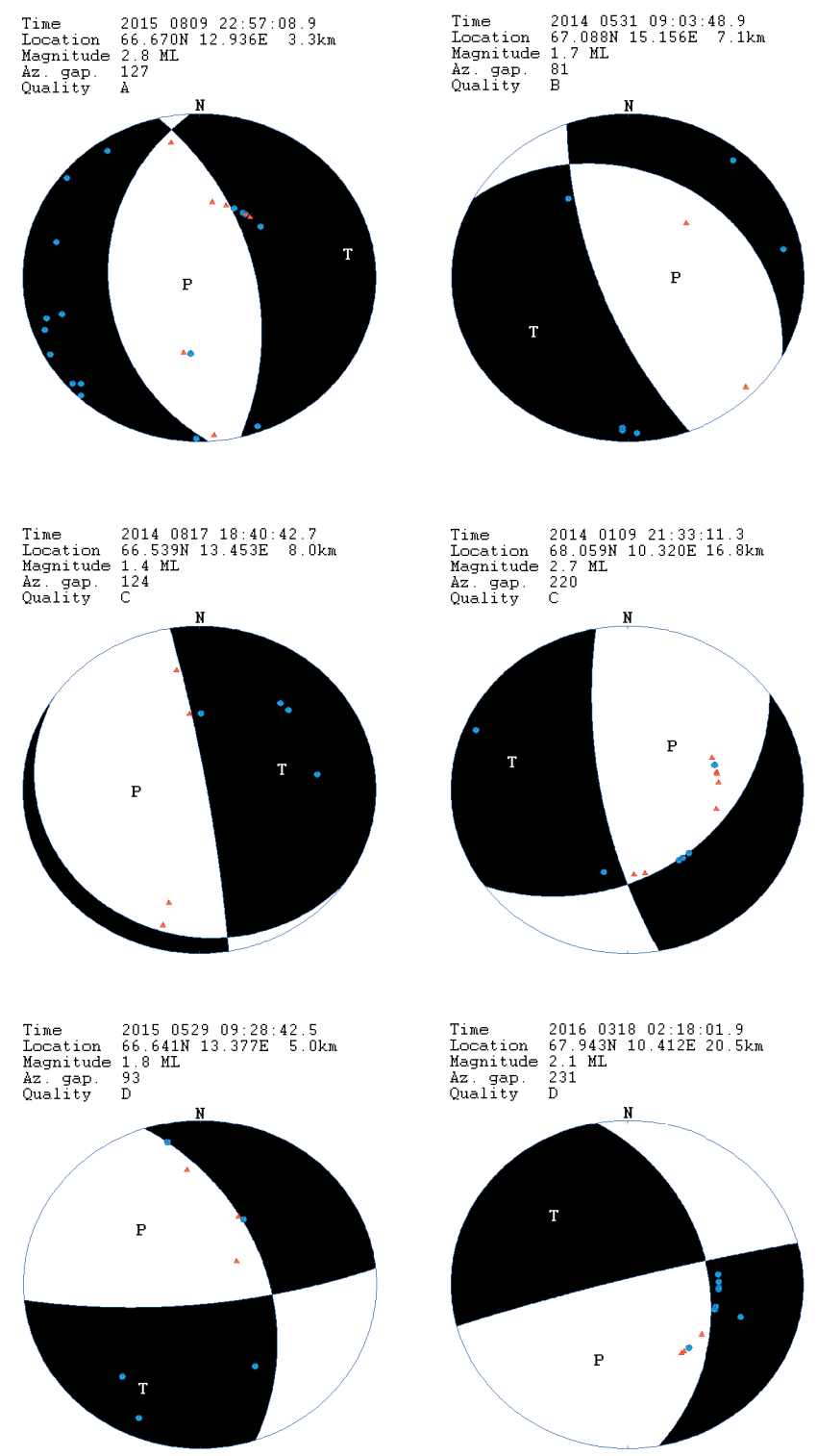

Figure 3. Examples of focal mechanisms of qualities $A, B, C$ and $D$ of selected onshore and offshore earthquakes. A stands for best quality results, while D stands for lowest quality, i.e., least trustworthy, results. The earthquake information (origin time, location, magnitude and azimuthal gap) and the assigned quality factor are noted above the depicted focal mechanisms. The results were obtained with the FOCMEC program under the SEISAN program package. Quality A (upper left) and B (upper right) were assigned to the focal mechanisms of the onshore earthquakes only, while quality $C$ (middle right) and D (bottom right) were assigned to the focal mechanisms of the offshore earthquakes mainly due to the generally larger azimuthal gaps. About 80\% of the focal mechanisms of the onshore earthquakes were assigned with the lower quality $C$ (middle left) and D (bottom left). On the focal sphere, the blue discs indicate firstmotion compressional observations (polarity ' $u p$ '), while red triangles indicate dilatational first-motion observations (polarity 'down'). T shows the calculated tensional axis, i.e., minimum compressional stress trend, and $P$ shows the pressure axis, i.e., maximum compressional stress trend. Theoretically, the compressional observations (blue discs) should fall within the tensional (black) quadrants, and the dilatational observations (red triangles) within the pressure (white) quadrants. If that was not the case in the calculated focal mechanism solution, those observations were considered as polarity errors. For instance, the quality A focal mechanism (upper left) solution has 3 polarity errors, the quality $C$ focal mechanism (middle right) has one polarity error, and the quality $D$ focal mechanism (bottom right) has one polarity error in their final results. 
their multiplication factors with lower weights 0.4 and 0.2 , respectively. The last constant of 1.5 (Eq. 1) ensures the approximate boundaries between 0 and 3 . In a theoretical case, when an earthquake has ten observations with comp $=$ res $=g a p=0$, then $q f=2.5$, which is the minimum requirement for quality $\mathrm{A}$.

The focal mechanisms with few observations are less reliable, and therefore we set additional requirements for such focal mechanisms: if $o b s \leq 6.5$, then the highest possible quality could be $\mathrm{C}$, and if $o b s \leq 5.5$ then the highest possible quality could be $\mathrm{D}$ only. The focal mechanisms of quality D with six or fewer observations are the least reliable (marked as 'D-' in Electronic Supplement 1; Inset of Fig. 4A).

Using the developed relation (Eq. 1) we assigned quality factors for 123 newly obtained focal mechanisms, while for 29 focal mechanisms from previous studies we retained the originally provided quality factors (Fig. 4A). $20 \%$ of the analysed dataset consists of the higher quality A and B solutions that were assigned to only the onshore earthquakes, whereas the focal mechanisms of the offshore earthquakes were assigned with the qualities $\mathrm{C}$ and $\mathrm{D}$ mostly due to the larger azimuthal gaps.

In our dataset, the average number of polarity readings for the onshore earthquakes was 7.8, and 12.4 for the offshore earthquakes, which was also related to the higher detection threshold offshore, i.e., generally stronger $(M \geq$ 1.2) recorded earthquakes. Onshore, the average number of calculated $\mathrm{P} / \mathrm{S}$ amplitude ratios was 2.7 , and 1.8 offshore, because many offshore earthquakes occurred far away from the network and therefore the direct waves were not the first arrivals. In the dataset, the largest number of observed polarities was 28 for an offshore earthquake of M 3.1. As the event occurred far away from the shore, the $\mathrm{P} / \mathrm{S}$ amplitude ratios could not be used. Moreover, due to the large azimuthal gap (larger than 200 degrees) and differences in the solutions across the three calculation methods (the final FOCMEC solution showed no polarity errors), using the developed relation (Eq. 1) the quality of the focal mechanisms was set to C. Onshore we obtained two focal mechanisms - one of $\mathrm{M}$ 3.2 from the earthquake swarm and one of M 2.8 to the southwest of Svartisen - with 25 polarity readings and up to 8 amplitude readings, but with smaller azimuthal gaps compared with the offshore earthquake. Both focal mechanisms were assigned with quality A, even though their final solutions contained up to 4 polarity errors and several errors of amplitude ratios.

\section{Analysis of the focal mechanisms}

An earthquake focal mechanism provides the direction of slip and the orientation of the fault on which the earthquake occurred. While the absolute magnitudes of stresses cannot be resolved, the directions of the stresses (i.e., $\sigma_{1}, \sigma_{2}, \sigma_{3}$ ) can be obtained. These stresses are commonly rotated into the horizontal and vertical stresses (e.g., Lund \& Townend, 2007) leading to the maximum horizontal stress axis, $\sigma_{H}$, the minimum horizontal stress axis, $\sigma_{h}$, and the vertical stress axis, $\sigma_{z}$. The relative shear-stress magnitude strongly influences whether the fault is susceptible to rupture, and the most decisive parameter is the ratio between the maximum and minimum stress magnitudes. In this study we used the simplified approach of focal mechanisms, and we were focused on $\sigma_{\mathrm{H}}$, since we could not resolve the stress ratio, only the $\sigma_{\mathrm{H}}$ trend, which can be related to regional stress models that are tectonically driven on the global scale. In addition, when many high quality earthquake focal mechanisms are available from a small region, reflecting on a homogeneous stress field, $\sigma_{1}$ can be calculated from an inversion of the focal mechanisms. We attempted to conduct such an inversion for a group of earthquakes to the west of Svartisen, but the inversion failed due to nonhomogeneity of the focal mechanism solutions (i.e., the convergence failed).

In our analysis we distinguished geographically several groups of earthquakes, while the grouping (Fig. 2A) was based on a hypothesis that earthquakes in the same area reflect on the same stresses and structures (i.e., underlaying tectonics), and it is therefore expected that the focal mechanisms in the group exhibit similarities in their source mechanisms. In this study, we analysed the focal mechanisms in terms of faulting type, distribution of azimuths of the nodal planes and calculated stress directions. During the analysis we took into account the solutions of all qualities based on an assumption that also low-quality focal mechanisms provide valuable information, albeit of a more uncertain nature. However, in the areas where also higher quality solutions (i.e., $\mathrm{A}$ and B) were available, we trusted more the results obtained from the latter solutions. The higher quality solutions in our dataset were assigned to $20 \%$ of the focal mechanisms of the earthquakes onshore or close to the shoreline, but unfortunately there were none offshore.

A focal mechanism derived using traditional (i.e., doublecouple assumption) methods is non-unique in terms of source rupture: two fault (nodal) planes are equally plausible as an earthquake source from an observational perspective. Only by using additional and independent geological information can a real rupture plane be identified from the two nodal plane candidates. Therefore, it is not possible to directly link the defined focal mechanisms to any well-mapped or well-known faults, and both nodal planes must be considered as equally plausible candidates for the rupture plane. However, by 

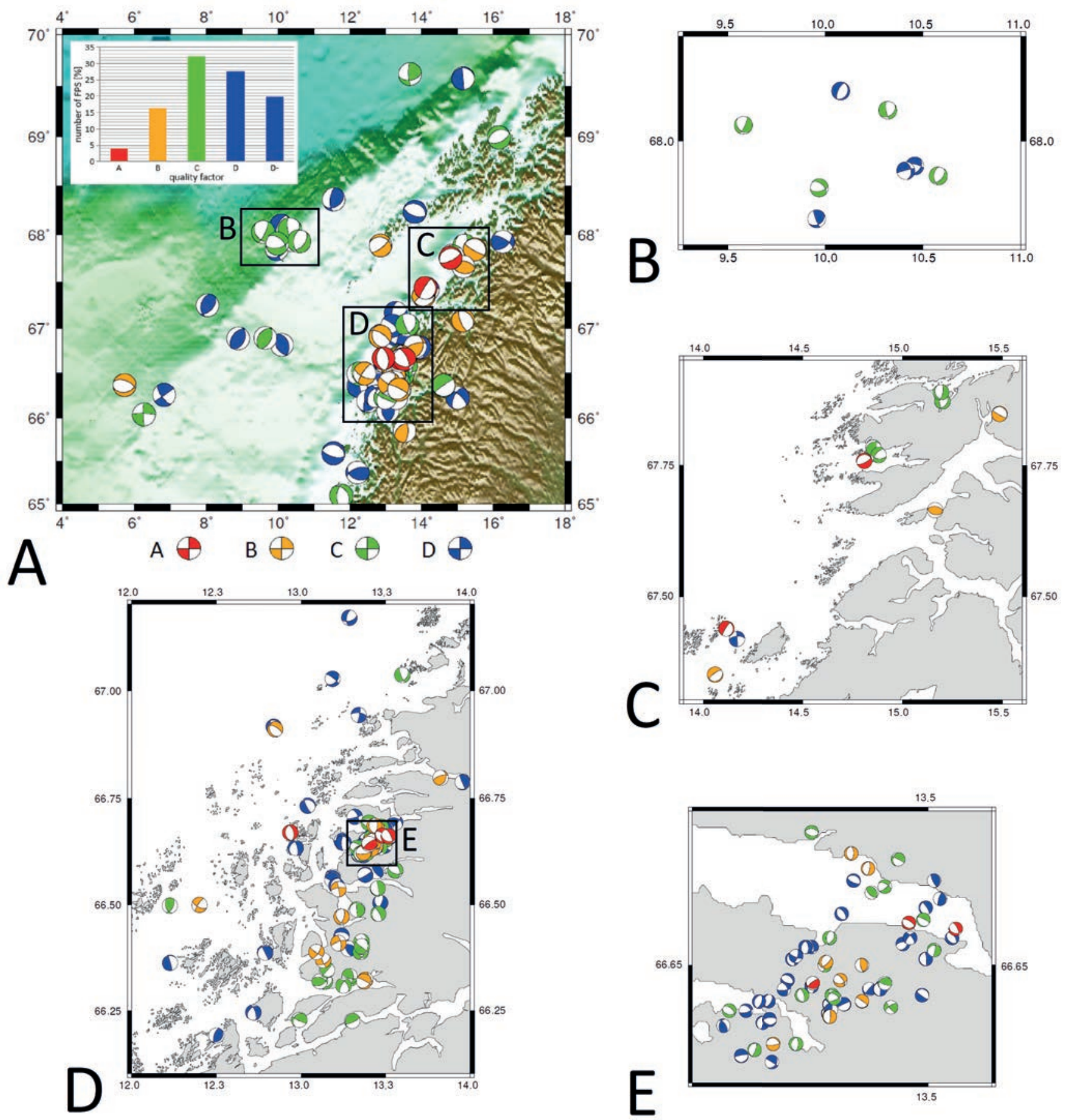

Figure 4. Final dataset of 152 focal mechanism solutions with indicated colour-coded quality factors: $(A)$ in the entire Nordland area, (B) along the continental shelf area, to the north of the Tronadjupet, $(C)$ around the Steigen area, $(D)$ the most seismically active coastal onshore area, and $(E)$ the earthquake swarm area to the west of Svartisen. Inset in (A): Distribution of quality factors of the focal mechanisms from best quality $A$ through $B$ and $C$ to reasonable quality D. 'D-' marks focal mechanisms with 6 or less observations.

plotting the azimuths of both nodal planes it may be possible to reveal dominant trends that may reflect on seismically active structures. Our results indicated that the azimuths of nodal planes obtained from the earthquake focal mechanisms in different areas matched quite well with the azimuthal trends of the mapped faults along the shelf edge, coastline and around Svartisen (Figs. 1 \& 5).
In addition, the type of faulting derived from the focal mechanisms may be used to relate earthquakes to particular tectonic structures. The majority of the obtained focal mechanisms are not pure, but rather mixtures of faulting types (i.e., oblique), and therefore the triangle plots suggested by Frohlich \& Apperson (1992) proved to be very useful in our study to reveal the dominant types of faulting (Fig. 5). Our results indicated a dominant 


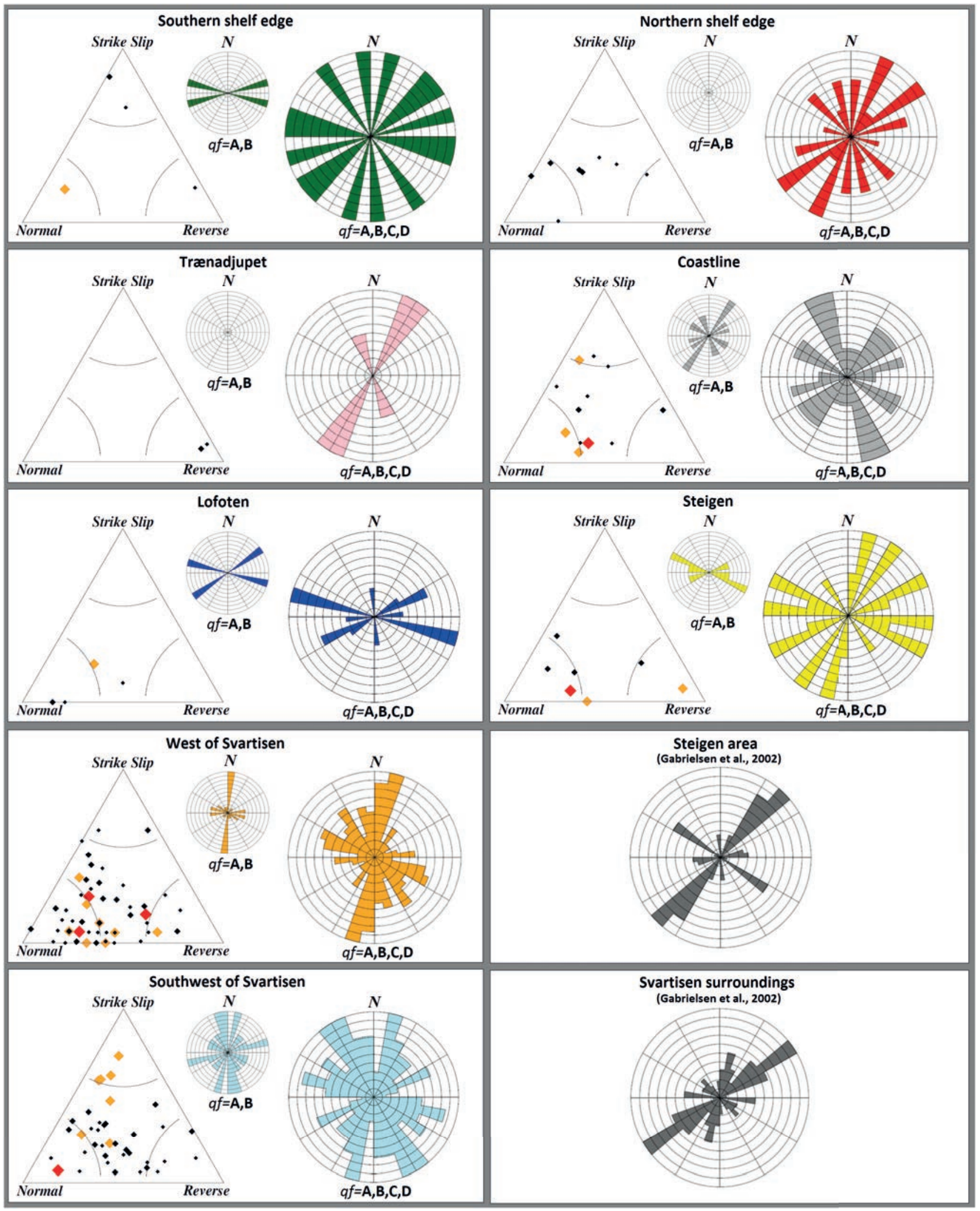

Figure 5. Panels indicate the results obtained from analysis of the focal mechanisms in different regions of Nordland. Triangle plots show type of faulting obtained from focal mechanisms of different qualities: red - quality A, orange - quality B, black - quality $C$ (bigger diamonds) and $D$ (smaller diamonds). The rose diagrams indicate the azimuths of nodal plane directions obtained from the focal mechanisms of quality $A$ and $B$ only (smaller rose diagrams), and of all qualities A to D (bigger rose diagram). Empty rose diagrams, in the Tronadjupet and the northern shelf edge areas, mean that there is no data of quality $A$ and B. For comparison, we also provide the trends of azimuths of the lineaments mapped on the surface by Gabrielsen et al. (2002) around Steigen and Svartisen, where the most intense onshore seismicity was recorded (lower right). 

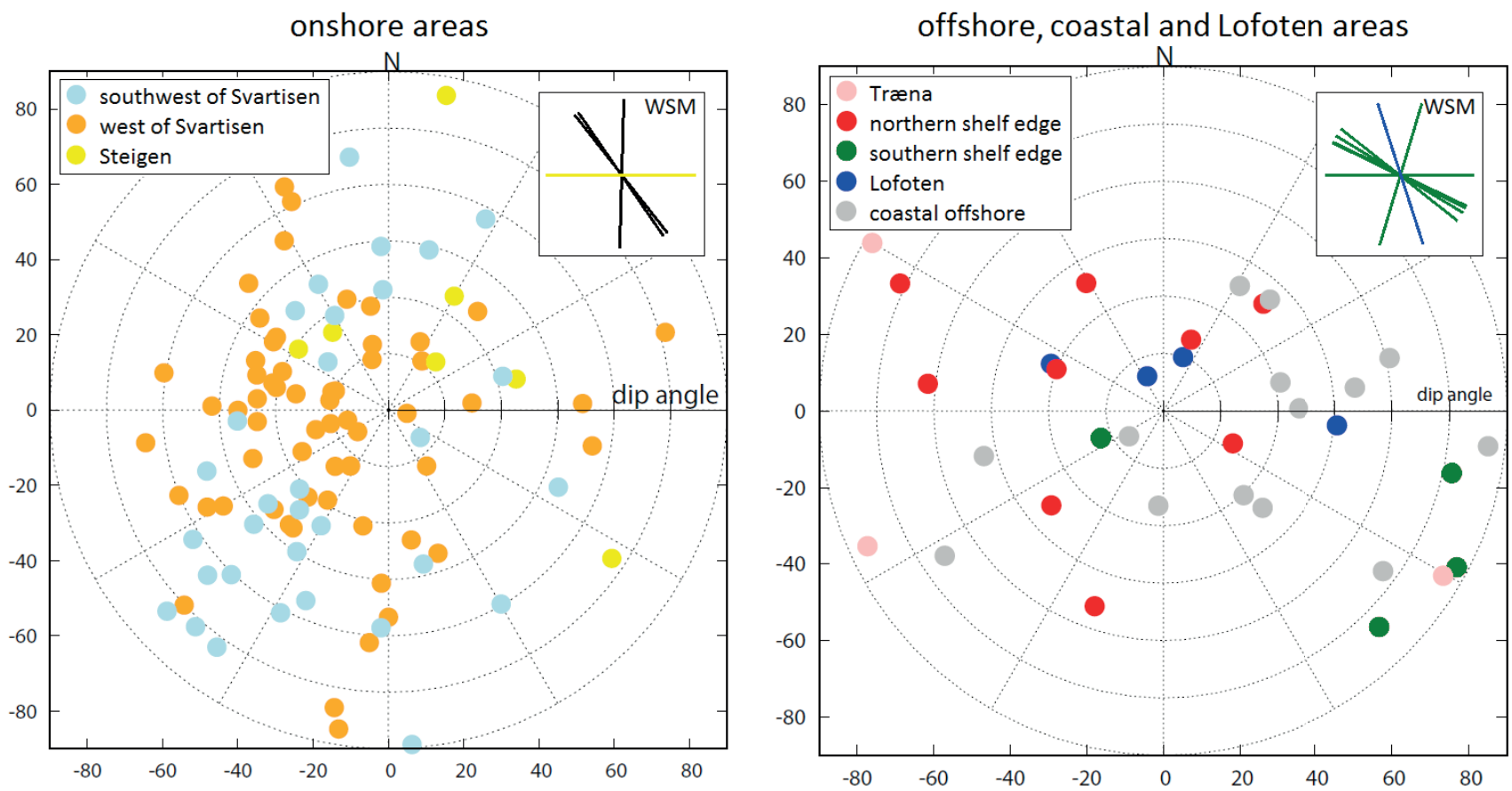

Figure 6. Azimuth and dip of maximum compression axis, $\sigma_{l}$, obtained from the focal mechanisms in Nordland in the onshore and offshore areas. Insets show horizontal compression axis, $\sigma_{H}$ from the WSM project colour-coded according to different regions, while in black we indicate data from the onshore areas which are outside the specified regions, i.e., east and southeast of Svartisen. As the WSM data were usually obtained from boreholes, they are limited to the uppermost $2 \mathrm{~km}$, whereas earthquakes, especially those offshore and in the Lofotens, are generally deeper.

normal type in the majority of the distinguished groups onshore. Moreover, the horizontal compression axis, $\mathrm{sH}$, trends obtained from normal or very oblique faulting types are dubious as s1 direction is subvertical. Therefore, to derive $\sigma_{\mathrm{H}}$ directions from focal mechanisms we used recommendations and software by Lund \& Townend (2007), and thus obtained the azimuth and dip of the $\sigma_{1}$ vectors (Fig. 6).

\section{Results and discussion}

Below we discuss in more detail our observations and results obtained from the earthquake focal mechanisms in four specific areas.

\section{West and southwest of Svartisen}

The area to the west of the Svartisen glacier was the seismically most active during the NEONOR2 monitoring period. Here we also recorded an earthquake swarm with several hundreds of small earthquakes which occurred from April 2015 to March 2016. From all the swarm events we obtained 61 focal mechanisms, which mostly indicated normal faulting (Figs. 4E \& 5). Also, dominant normal to strike-slip faulting was observed southwest of Svartisen from the analysis of 39 focal mechanisms (Figs. $4 \mathrm{D} \& 5)$. The earthquakes in both areas were generally shallow (3 to $8 \mathrm{~km}$ deep; Fig. 2B) and many earthquakes in the southwestern part clustered along well-defined NW-SE-trending lines, indicating that the earthquakes probably migrated along the structures, which were interpreted as active faults (Janutyte et al., 2017). The azimuths of nodal planes (Fig. 5) obtained from the focal mechanisms showed two clear trends: a NNE-SSW trend to the west of Svartisen, and a somewhat bimodal trend to the southwest of Svartisen with the nodal planes of NNW-SSE (along migration paths of the earthquakes) and NNE-SSW trends. These observations coincide quite well with the structural trends mapped by Gabrielsen et al. (2002) in the surroundings of Svartisen (Fig. 5).

The Svartisen massif (SV; Fig. 1) in Nordland is a c. 1000 $\mathrm{m}$-high mountain hosting an ice sheet. Due to its steep relief, the massif is a likely candidate for local stress sources in the area. It was also found that the massif, including its peripheral regions, to a large extent consists of very poor quality rock with large cracks and faults allowing water (from precipitation and snowmelt) to easily penetrate from the glaciated regions to its periphery. Water lubricates the faults such that the friction is reduced and therefore smaller changes in stress conditions would be required to trigger earthquakes along the faults. This is a likely mechanism behind the earthquake swarm activity which was recorded at the western foot of the Svartisen massif from the spring of 2015. While modelling would be appropriate for long-term changes in the ice sheet, the observed intense local seismicity on the fringes of the massif indicate that short-term changes in the glacier might indeed influence the earthquake occurrence in the 
area. However, the NEONOR2 monitoring did not cover a sufficiently long time window to confirm this.

Analysis showed that $\sigma_{\mathrm{H}}$ directions in different groups of earthquakes around Svartisen - 61 focal mechanisms to the west, 39 to the southwest, two to the north, one to the northwest and one to the southeast of the glacier - are almost tangential to the glacier, which would coincide with an assumption of local uplift due to the retreat (melting) of the glacier. However, it must be taken into account that the dominant type of faulting is normal, thus $\sigma_{1}$ directions are not very clear. Moreover, the lower quality $\mathrm{C}$ and $\mathrm{D}$ focal mechanisms obtained from single earthquakes, as it is in this case, might be uncertain; therefore, these results should be treated with caution. However, it is also important to note that the data on hand show a possible correlation between the earthquake swarm activity and the glacier.

As the earthquake swarm was recorded only once and did not repeat within the yearly cycle, it could therefore be concluded that other factors, not only the changes in the ice mass, could affect the earthquake occurrence in the area. Another possible stress source in the area is the Storglomvatn hydroelectric power station and lake, located to the north of Svartisen, with a capacity of 3.5 * $10^{9} \mathrm{~m}^{3}$ and a height of 128 metres. The power plant experiences large variations in water-filling cycles, and thus the changes in the water mass might significantly change the rock stresses and lubrication patterns around the area, although there is not enough data to allow us to hypothesise about the size of its effects on the local stress field. However, it is likely that significant changes in the lake level of Storglomvatn could reflect on the focal mechanisms of the shallow earthquakes.

\section{Steigen and Lofoten area}

The earthquakes in Steigen and Lofoten exhibited a dominant normal faulting type, with some high-quality focal mechanisms showing also reverse faulting around Steigen (Figs. 4C \& 5). The hypocentre depth around Steigen was mostly shallow (down to $10 \mathrm{~km}$ depth) while it was somewhat deeper in the Lofoten area (down to $20 \mathrm{~km}$ depth; Fig. 2B). Even though the obtained focal mechanisms were not homogeneous in the Steigen area, the tendency for a NE-SW compression could be distinguished (Fig. 5). Moreover, the azimuths of nodal plane directions trending from NNE-SSW to ENEWSW obtained from the focal mechanisms are consistent with the lineaments recorded by Gabrielsen \& Ramberg (1979), and also with the direction of the nodal plane of the composite focal mechanism obtained by Atakan et al. (1994) from the Steigen earthquake sequences. The NNESSW trend (Gabrielsen \& Ramberg, 1979) is parallel to the Vestfiord Basin and some post-Caledonian faults which were active in post-glacial times (Grønlie, 1922). This might indicate that faults and structures mapped on the surface are indeed active down to some depth.

In the Lofoten area, the azimuths of nodal planes showed a preference for the WNW-ESE trend, which is similar to the trends obtained by Gabrielsen \& Ramberg (1979). The normal faulting in this area was also earlier observed by Hicks (1996) from a single-event focal mechanism that also indicated a coast-perpendicular extension. With a dominant normal faulting type the maximum compressional direction remained inconclusive (Figs. 4 A, 5 \& 6), while one borehole (WSM data) in the area indicated compressional stresses trending NNW-SSE (Figs. 1 \& 6).

\section{Coastal area}

Along the coast the focal mechanisms indicated normal to strike-slip faulting (Fig. 5). The obtained $\sigma_{1}$ direction (Fig. 6) was bimodal, but with a slight preference for the NW-SE trend (i.e., coast-perpendicular compression). The azimuths of the nodal planes obtained from all focal mechanisms in the area indicated a dominant NNWSSE trend, possibly due to the westerly extensions of the onshore faults, while several higher quality A and B focal mechanisms further to the north, closer to Steigen indicated NNE-SSW direction, which is parallel to the Vestfjord Basin and some post-Caledonian faults (e.g., Gabrielsen \& Ramberg, 1979).

Around Meløy, Gabrielsen \& Ramberg (1979) indicated the NNW-SSE-striking fault population as a likely candidate for earthquake occurrence, while NNE-SSWtrending active faults were reported by Bungum \& Husebye (1979) from the Meløy earthquake swarm.

In an area about $30 \mathrm{~km}$ north of Meløy we obtained two focal mechanisms. Both focal mechanisms were of low quality $\mathrm{D}$, and therefore might not be very reliable. However, from the locations we related the earthquakes to the NE-SW-trending Grønna structure (Fig. 1).

\section{Offshore areas}

In the offshore areas, the new focal mechanisms were of quality $\mathrm{C}$ and $\mathrm{D}$, mainly reflecting the larger azimuthal gaps (Fig. 4A). On the other hand, the recorded earthquakes along the shelf edge were generally stronger $(M \geq 1.2)$ and should therefore reflect the regional trends better. Also, due to larger source-to-receiver distances (more than $140 \mathrm{~km}$ ), the $\mathrm{P} / \mathrm{S}$ amplitude ratios could not be used, as they are applicable to direct P- and S-waves only. Consequently, we defined many focal mechanisms of the offshore earthquakes using only P-wave polarities. We separated the offshore region into three areas: the Trænadjupet, and the southern and the northern parts of the shelf edge (Fig. 2A). Around Trænadjupet the new and earlier data (Bungum et al., 1991) showed pure 
reverse faulting as well as one earthquake slightly farther to the northwest of the Trænadjupet (Fig. 4A). These earthquakes clearly signify a $\sigma_{\mathrm{H}}$ of NW-SE trend, which is in compliance with the ridge push of plate tectonics. The $\mathrm{E}-\mathrm{W}$ distribution of the epicentres at the northern tip of the Nordland Ridge does not match with any known fault azimuths. However, the NNE-SSW trends of the nodal planes (Fig. 5) coincide well with the mapped regional faults (Fig. 1), which could also indicate én echelon faulting.

To the south of Trænadjupet on the Vøring platform, two focal mechanisms denoted a strike-slip faulting while on the oceanic part of the shelf edge one earlier obtained focal mechanism indicated a normal faulting event (Fig. 4A). Here, we also obtained a NW-SE trend for $\sigma_{\mathrm{H}}$, which is consistent with the WSM data (Figs. 1 \& 6), and coincides with the ridge-push force. To the north of Trænadjupet along the shelf edge, the type of faulting was quite mixed while the nodal plane directions (Figs. 4B \& 5) obtained from the focal mechanisms showed a clear NE-SW trend, which is in alignment with the strikes of regional faults. The NW-SE trend of $\sigma_{1}$ (Fig. 6) here also indicated an influence from the ridge push. This trend also coincides well with the WSM data (Figs. 1 \& 6).

In summary, we found that onshore earthquake characteristics are very different from those of the offshore earthquakes. Onshore, the dominant faulting type is normal, whereas a rather mixed type is common for the offshore earthquakes. Offshore, the $\sigma_{1}$ direction indicated clear NW-SE compression, which is also consistent with the azimuths of the $\sigma_{\mathrm{H}}$ axis from the boreholes (Figs. 1 \& 6), and is in accord with the ridge-push force of plate tectonics (e.g., Richardson et al., 1979). Onshore, $\sigma_{1}$ trends are more scattered and most likely reflect on the local stress sources (such as topography) and possibly shortterm stress variations (e.g., around the Svartisen massif). The WSM borehole data onshore is very sparse and almost absent in some specific areas, and thus it is very difficult to correlate it with our results. However, when comparing $\sigma_{\mathrm{H}}$ trends obtained from boreholes and those from earthquakes one must bear in mind that the WSM data generally reflect the state of stress in the upper part of the crust (down to about $2 \mathrm{~km}$ ), whereas earthquakes generally generated in the deeper crust.

Both the onshore and the offshore focal mechanisms indicated the azimuths on nodal planes (Fig. 5) of mostly NW-SW trend, which is generally consistent with the mapped regional faults in Nordland (Fig. 1).

Along the shelf edge, the dominant stress source is the ridge push of NW-SE trend while the obtained azimuths of the nodal planes of the earthquakes mostly trend NE-SW (Figs. $1 \& 5$ ), which in general is perpendicular to $\sigma_{\mathrm{H}}$. According to the Andersonian model (e.g., Anderson, 1905), for a fault of this orientation to rupture in such a stress field, the fault must have an inclination that favours the shear stresses.
Therefore, we assume that the offshore faults at a seismogenic depth (about $20 \mathrm{~km}$ deep) are somewhat inclined. However, some of the azimuths of the nodal planes obtained offshore indicate a NW-SE trend that is parallel to the regional stress field. Onshore, the Mid-Atlantic ridge push is dominated by the local stress sources (e.g., steep topography), as here we observe clear deviations from the regional stress pattern (Fig. 6). The extreme topography in the region with steep mountains and deep fjords should create substantial local vertical stresses that favour normal faulting, which we have in fact observed as the dominant type of faulting in the onshore areas of Nordland.

\section{Conclusions}

We compiled a dataset of 152 focal mechanisms for Nordland, northern Norway, that consists of 123 newly obtained focal mechanisms from the NEONOR2 project and 39 focal mechanisms from earlier studies. The dataset is now made available and presented here (Electronic Supplement 1) to help promote future investigations on this database.

We analysed the focal mechanisms in terms of faulting type, directions of azimuths of nodal planes and maximum compressional stress directions. The results shed more light on the stress conditions in this part of Norway. Our main conclusions are as follows:

- We developed a focal mechanism quality ranging system that was specifically adjusted to the new data. Using the developed relation (Eq. 1) we assigned the new 123 focal mechanisms with quality factors from best quality A to lowest quality $\mathrm{D}$, while for the 39 focal mechanisms from earlier studies we maintained the quality factor as originally provided.

- Qualities A and B weres assigned to about $20 \%$ of all obtained focal mechanisms. The higher quality was assigned to the onshore earthquakes mainly because of their better station coverage compared to the earthquakes offshore where only lower quality, C and D, was assigned to the new focal mechanisms. In our study we analysed focal mechanism solutions of all qualities, as even low-quality results are valuable and carry information that contributes to recognising the general trends. However, we trusted more the results obtained from higher quality A and B focal mechanisms in the areas where such results were available.

- Onshore Nordland, the dominant faulting type is normal, while along the coast it is mostly normal to strike-slip, and in the offshore areas it is rather of a mixed character.

- In the offshore areas, strikes of the nodal planes obtained from the focal mechanisms mostly follow a NE-SW 
trend, which is subparallel to the coastline and coincides with the mapped structural trends on the continental shelf, indicating that present-day earthquakes do indeed reactivate these old structures. In the onshore area of Nordland we resolved two dominant trends of azimuths of the nodal planes: the major trend is NNE-SSW, and the weaker trend WNW-ESE. Such a nodal plane distribution of the onshore earthquakes also coincides with trends of the structures mapped by Gabrielsen et al. (2002). Therefore, it can be concluded that the geologically mapped onshore structures might be seismically active and do reflect the present-day crustal deformation.

- The obtained maximum compression axis, $\sigma_{1}$, in the offshore areas indicated a clear NW-SE trend reflecting on the expected plate-tectonic ridge push. The maximum horizontal stress axis, $\sigma_{\mathrm{H}}$, recorded in the onshore areas is more scattered and therefore related to the local stress sources, such as topography. Moreover, we interpreted the observed tendency of $\sigma_{H}$ to follow the tangential direction to the Svartisen glacier as a manifestation of the influence of the changes in the ice-sheet and related processes (i.e., melting, accumulation, etc.), which, most likely, is one of the causes of the enhanced earthquake occurrence in the area. Offshore, the obtained compressional stress directions are consistent with the borehole breakouts from the World Stress Map (WSM) database, while onshore the obtained results partly correlate with the WSM data.

- As we observed seismicity along the shelf edge on NE-SW-trending faults, we concluded that the faults at seismogenic depth should be inclined, as this would satisfy rupturing conditions in the stress field from the NW-SE-oriented ridge-push force. Onshore, local stresses dominate mainly due to the steep topography that would invoke vertical stresses that favour normal faulting, which was observed in the onshore areas.

- From the three recorded seismic swarms in the Nordland area around Meløy in 1978-1979, Steigen in 1992 and to the west of Svartisen in 2015-2016, it could be concluded that shallow foci and extensional tectonics are the characteristic features of swarm activity in the coastal regions of Nordland.

Generally, the results showed that the seismicity onshore and offshore Nordland is different in character, with mostly deeper mixed faulting earthquakes offshore where stresses arising from the Mid-Atlantic ridge push dominate; and with mostly shallow, normal-faulting earthquakes onshore where local stresses rule over the regional stress pattern, while along the coast the faulting regime was mostly normal to strike-slip.
Acknowledgements. The present work was conducted with the support of the Norwegian Research Council to the Norwegian Geological Survey under grant number 228105/E30, and with additional funding from Aker BP, DEA, DONG Energy, E.ON, the Geological Survey of Norway (NGU), the Norwegian Mapping Authority (Kartverket), Lundin Norway, Maersk Oil, Noreco, NORSAR, Norske Shell, the Norwegian Petroleum Directorate, Repsol, Statoil and VNG. The primary earthquake locations used in our staudy were obtained at the Univerity of Bergen. We thank Björn Lund and John Townend for sharing with us their software on calculating horizontal stress orientations. We greatly appreciate the contributions of Odleiv Olesen and Yuriy Maystrenko through countless discussions. We also thank Roy H. Gabrielsen and an anonymous reviewers for their very useful comments and suggestions that greatly improved this manuscript.

\section{References}

Anderson, E.M. 1905: The dynamics of faulting. Transactions of the Edinburgh Geological Society 8, 387-402. https://doi.org/10.1144/transed.8.3.387.

Atakan, K., Lindholm, C.D. \& Havskov, J. 1994: Earthquake swarm in Steigen, northern Norway: an unusual example of intraplate seismicity. Terra Nova 6, 180-194. https://doi.org/10.1111/j.1365-3121.1994.tb00652.x.

Blystad P., Brekke, H., Færseth, R., Larsen, B.T., Skogseid, J. \& Tørudbakken, B. 1995: Structural elements of the Norwegian continental shelf. Part II: The Norwegian Sea Region. Norwegian Petroleum Directorate Bulleting 8, 45 pp.

Braathen, A., Osmundsen, P.T., Nordgulen, Ø. \& Roberts, D. 2002: Orogen-parallel, extensional denudation of the Caledonides in North Norway. Norsk Geologisk Tidsskrift 82, 225-241.

Bungum, H. \& Husebye, E.S. 1979: The Meløy, northern Norway, earthquake sequence - a unique intraplate phenomenon. Norsk Geologisk Tidsskrift 59, 189-193.

Bungum, H. \& Olesen, O. 2005: The 31st of August 1819 Lurøy earthquake revisited. Norwegian Journal of Geology 85, 245-252.

Bungum, H., Hokland, B.K., Husebye, E.S. \& Ringdal, F. 1979: An exceptional intraplate earthquake sequence in Meløy, Northern Norway. Nature 280, 32-35. https://doi.org/10.1038/280032a0.

Bungum, H., Vaage, S. \& Husebye, E.S. 1982: The Meløy earthquake sequence, Northern Norway; source parameters and their scaling relations. Bulletin of the Seismological Society of America 72, 197-206.

Bungum, H., Alsaker, A., Kvamme, L.B. \& Hansen, R.A. 1991: Seismicity and seismotectonics of Norway and surrounding continental shelf areas. Journal of Geophysical Research 96, 2249-2265. https://doi.org/10.1029/90JB02010.

Bungum, H., Olesen, O., Pascal, C., Gibbons, S., Lindholm, C. \& Vestøl, O. 2010: To what extent is the present seismicity of Norway driven by post-glacial rebound? Journal of the Geological Society 167, 373384. https://doi.org/10.1144/0016-76492009-009.

Byrkjeland, U., Bungum, H. \& Eldholm, O. 2000: Seismotectonics of the Norwegian continental margin. Journal of Geophysical Research 105, 6221-6236. https://doi.org/10.1029/1999JB900275.

Dehls, J.F. \& Olesen, O. 2000: NEONOR: Neotectonics in Norway: Annual Technical Report 1999. Norges geologiske undersøkelse Report 2000.001, 207 pp.

Eide, E.A., Osmundsen, P.T., Meyer, G.B., Kendrick, M.A. \& Corfu, F. 2002: The Nesna Shear Zone, north-central Norway: an ${ }^{40} \mathrm{Ar} /{ }^{39} \mathrm{Ar}$ record of Early Devonian - Early Carboniferous ductile extension and unroofing. Norwegian Journal of Geology 82, 317-339.

Fejerskov, M. \& Lindholm, C. 2000: Crustal stresses in and around Norway; an evaluation of stress generating mechanisms. In Nottvedt, A. (ed.): Dynamics of the Norwegian Margin, Geological Society of London Special Publication 167, pp. 451-467. 
Frohlich, C. \& Apperson, K.D. 1992: Earthquake focal mechanisms, moment tensors, and the consistency of seismic activity near plate boundaries. Tectonics 11, 279-296. https://doi.org/10.1029/91TC02888.

Gabrielsen, R.H. \& Ramberg, L.B. 1979: Fracture paterns in Norway from Landsat imagery: results and potential use. Proceedings, Norwegian Petroleum Society, Norwegian Sea Symposium, Tromso, NSS/123, 1-23.

Gabrielsen, R.H., Braathen, A., Dehls, J. \& Roberts, D. 2002: Tectonic lineaments of Norway. Norsk Geologisk Tidsskrift 82, 153-174.

Gregersen, S. \& Voss, P. 2009: Stress change over short geological time: the case of Scandinavia over 9000 years since the Ice Age. In Reicherter, K., Michetti, A.M. \& Silva, P.G. (eds.): Palaeoseismology: Historical and Prehistorical Records of Earthquake Ground Effects for Seismic Hazard Assessment, Geological Society of London Special Publications 316, 217-235. https://doi.org/10.1144/SP316.10.

Grønlie, O.T. 1922: Strandlinjer, moræner og skjælforekomster i den sydlige del av Troms fylke. Norges geologiske undersøkelse 94, 1-39.

Gudmundsson, A. 1999: Postglacial crustal doming, stresses and fracture formation with application to Norway. Tectonophysics 307, 407-419. https://doi.org/10.1016/S0040-1951(99)00107-9.

Hardebeck, J.L. \& Shearer, P.M. 2002: A new method for determining first motion focal mechanisms. Bulletin of the Seismological Society of America 92, 2264-2276. https://doi.org/10.1785/0120010200.

Heidbach, O., Tingay, M., Barth, A., Reinecker, J., Kurfeß, D. \& Müller, B. 2008: The World Stress Map database release 2008. DOU:10.1594/ GFZ.WSM.Rel2008, 2008.

Heidbach, O., Tingay, M., Barth, A., Reinecker, J., Kurfeß, D. \& Müller, B. 2010: Global crustal stress pattern based on the World Stress Map database release 2008. Tectonophys 482, 3-15. https://doi.org/10.1016/j.tecto.2009.07.023.

Hicks, E.C. 1996: Crustal stresses in Norway and surrounding areas as derived from earthquake focal mechanism solutions and in situ stress measurements. PhD thesis, University of Oslo, Norway, 164 pp.

Hicks, E.C., Bungum, H. \& Lindholm, C.D. 2000a: Seismic activity, inferred crustal stresses and seismotectonics in the Rana region, northern Norway. Quaternary Science Reviews 19, 1423-1436. https://doi.org/10.1016/S0277-3791(00)00071-8.

Hicks, E.C., Bungum, H. \& Lindholm, C.D. 2000b: Stress inversion of earthquake focal mechanism solutions from onshore and offshore Norway. Norsk Geologisk Tidsskrift 80, 235-250. https://doi.org/10.1080/00291960051030545.

Jaeger, J.C., Cook, N.G.W. \& Zimmerman, R.W. 2007: Fundamentals of Rock Mechanics. 4th edition. Blackwell Publishing, Oxford, 475 pp.

Janutyte, I., Lindholm, C. \& Olesen, O. (2017): Relation between seismicity and tectonic structures offshore and onshore Nordland, northern Norway. Norwegian Journal of Geology 97, 211-225. https://dx.doi.org/10.17850/njg97-3-02.

Lund, B. \& Townend, J. 2007: Calculating horizontal stress orientations with full or partial knowledge of the tectonic stress tensor. Geophysical Journal International 170, 1328-1335.

https://doi.org/10.1111/j.1365-246X.2007.03468.x.

Maystrenko Y., Olesen, O., Gernigon, L. \& Gradmann, S. 2017: Deep structure of the Lofoten-Vesterålen segment of the Mid-Norwegian continental margin and adjacent areas derived from 3D density modeling. Journal of Geophysical Research, Solid Earth 122, 14021433. https://doi.org/10.1002/2016JB013443.

Muir Wood, R. 1989: Extraordinary deglaciation reverse faulting in northern Fennoscandia. In Gregersen, S. \& Basham, P.W. (eds.): Earthquakes at North Atlantic Passive Margins: Neotectonics and Postglacial Rebound, NATO ASI Series, Series C: Mathematical and Physical Sciences 266, pp. 141-173.

Olesen, O., Lundin, E., Nordgulen, Ø., Osmundsen, P.T., Skilbrei, J.R., Smethurst, M.A., Solli, A., Bugge, T. \& Fichler, C. 2002: Bridging the gap between the Nordland onshore and offshore geology. Norwegian Journal of Geology 82, 243-262.
Olesen, O., Bungum, H., Dehls, J., Lindholm, C., Pascal, C. \& Roberts, D. 2013: Neotectonics, seismicity and contemporary stress field in Norway - mechanisms and implications. In Olsen, L., Fredin, O. \& Olesen, O. (eds.): Quaternary Geology of Norway, Norges geologiske undersøkelse Special Publication 13, pp. 145-174.

Osmundsen, P.T., Sommaruga, A., Skilbrei, J.R. \& Olesen, O. 2002: Deep structure of the Mid Norway Rifted Margin. Norwegian Journal of Geology 82, 205-224.

Osmundsen, P.T., Henderson, I., Lauknes, T.R., Larsen, Y., Redfield, T.F. \& Dehls, J. 2009: Tectonic controls on topography and mass-wasting processes in northern Norway. Geology 37, 135-138. https://doi.org/10.1130/G25208A.1.

Ottemoller, L., Voss, P. \& Havskov, J. 2016: Seisan earthquake analysis software for Windows, Solaris, Linux and MacOS, $534 \mathrm{pp}$.

Pascal, C. \& Gabrielsen, R.H. 2001: Numerical modeling of Cenozoic stress patterns in the mid-Norwegian margin and the northern North Sea. Tectonics 20, 585-599. https://doi.org/10.1029/2001TC900007.

Pascal, C., Roberts, D. \& Gabrielsen, R.H. 2005: Quantification of neotectonic stress orientations and magnitudes from field observations in Finnmark, northern Norway. Journal of Structural Geology 27, 859-870. https://doi.org/10.1016/j.jsg.2005.01.011.

Pascal, C., Roberts, D. \& Gabrielsen, R.H. 2010: Tectonic significance of present-day stress relief phenomena in formerly glaciated regions. Journal of the Geological Society of London 167, 363-371. https://doi.org/10.1144/0016-76492009-136.

Reasenberg, P. \& Oppenheimer, D. 1985: Fpfit, fpplot, and fppage: Fortran computer programs for calculating and displaying earthquake fault plane solutions. U.S. Geological Survey, Technical report 85-739, 109 pp.

Redfield, T.F. \& Osmundsen, P.T. 2013: The long-term topographic response of a continent adjacent to a hyperextended margin: A case study from Scandinavia. Geological Society of America Bulletin 125, 184-200. https://doi.org/10.1130/B30691.1.

Richardson R.M., Solomon, S.C. \& Sleep, N.H. 1979: Tectonic stress in plates. Reviews of Geophysics 17, 981-1019. https://doi.org/10.1029/RG017i005p00981.

Roberts, D. \& Gee, D.G. 1985: An introduction to the structure of the Scandinavian Caledonides. In Gee, D.G. \& Sturt, B.A. (eds.): The Caledonian Orogen - Scandinavia and related areas, John Wiley and Sons, Chichester, pp. 55-68.

Rykkelid, E. \& Andresen, A. 1994: Late Caledonian extension in the Lofoten area, northern Norway. Tectonophysics 231, 157-169. https://doi.org/10.1016/0040-1951(94)90127-9.

Sibson, R.H. 1985: A note on fault reactivation. Journal of Structural Geology 7, 751-754. https://doi.org/10.1016/0191-8141(85)90150-6.

Snoke, J.A., Munsey, J.W., Teague, A.G. \& Bollinger, G.A. 1984: A program for focal mechanism determination by combined use of polarity and SV-P amplitude ratio data. Earthquake Notes 55, 15 pp.

Stroeven A.P.,Hättestrand, C., Kleman,J.,Heyman,J.,Fabel,D., Fredin, O., Goodfellow, B.W., Harbor, J.M., Jansen, J.D., Olsen, L., Caffee, M.W., Fink, D., Lundqvist, J., Rosqvist, G.C., Strömberg, B. \& Jansson K.N. 2016: Deglaciation of Fennoscandia. Quaternary Science Reviews 147, 91-121. https://doi.org/10.1016/j.quascirev.2015.09.016.

Vaage, S. 1980: Seismic evidence of complex tectonics in the Meløy earthquake area. Norsk Geologisk Tidsskrift 60, 213-217.

Zoback, M.L. \& Zoback, M. 1989: Tectonic stress field of the conterminous United States. In Pakiser, L.C. \& Mooney, W.D. (eds.): Geophysical Framework of the Continental United States, Geological Society of America Memoir 172, pp. 523-539. https://doi.org/10.1130/MEM172-p523. 